\title{
Influence of Fly Ash on the Properties of Self-Compacting Fiber Reinforced Concrete
}

\author{
Abdullah Mohsen Ahmed Zeyad ${ }^{1 *}$ and Abdullah Mustafa Saba ${ }^{2}$ \\ ${ }^{1}$ Civil Engineering, College of Engineering, Jazan University, Jazan, Saudi Arabia \\ ${ }^{2}$ Materials Engineering, College of Engineering, Zagazig University, Zagazig, Egypt
}

\begin{abstract}
Self-compacting concrete (SCC) has high flow ability and high resistance to segregation and bleeding. These characteristics facilitate the mixing, casting and finishing of SCC without using compacting or vibrating machines. Adding mineral admixtures, such as fly ash (FA), and superplasticizers improves SCC properties by preventing segregation and bleeding and by increasing rheological parameters. SCC requires high flow ability under the influence of self-weight to completely fill all mold parts for full compaction. This paper discusses the results of an experimental investigation on the properties of SCC and self-compacting fiber reinforced concrete (SCFRC) mixtures with the inclusion of polypropylene fibers (PFs) and containing FA at replacement rates of $0 \%, 20 \%, 40 \%$, and $60 \%$ cement mass. The compressive, flexural, and split tensile strengths of the prepared concrete samples were investigated at ages of $7,14,28$, and 90 days. The workability of fresh concrete mixtures was also studied through segregation, bleeding, slump flow, slump flow T50, L-box V-funnel T5, and V-funnel tests. Results showed that the best properties of fresh SCCs were obtained when FA was added at replacement rates of $20 \%$ and $40 \%$ cement mass. In addition, the inclusion of PFs at a volumetric ratio of $0.22 \%$ decreased segregation and bleeding and improved the flexural and tensile strengths of SCFRCs.
\end{abstract}

Keywords: Compressive strength; Fly ash; Fresh concrete; Polypropylene fibers; Self-compacting concrete

\section{Introduction}

Self-compacting concrete (SCC) and self-compacting fiber reinforced concrete (SCFRC) are special types of concrete mixture that is characterized by high resistance to segregation and bleeding. SCC can be cast without compaction or vibration. Products made with SCC have high quality, excellent finish, and are virtually free of flaws, such as large voids, because of the excellent filling ability of SCC without honeycomb formation [1-5]

SCC is produced with the addition of fine industrial wastes, including fly ash (FA), silica fume, and furnace slag [6]. FA and some types of pozzolanic materials have been successfully used as mineral admixtures in SCC [4-7]. The addition of mineral admixtures results in the sufficient viscosity of SCC, consequently reducing bleeding, segregation, and plastic shrinkage. In addition to fine mineral admixtures, agricultural waste materials, including palm oil fuel ash or rice husk ash, can be used as admixtures in SCC $[8,9]$.

FA is added to concrete mixtures to prevent segregation and bleeding, increase flowability, and control hardened concrete properties, including compressive, indirect tensile, and flexural strengths [10-12]. The use of FA in SCC production requires the addition of a superplasticizer (SP) to the concrete mix to achieve high workability and appropriate mix proportions. A high SP dosage, however, increases bleeding and segregation in fresh concretes. These problems can be avoided by adding a viscosity-modifying admixture (VMA) to increase the viscosity of fresh concretes. Furthermore, the use of fine mineral admixtures can reduce the amount of SPs required to achieve the desired rheology. Moreover, the use of FA as an alternative material reduces the need for VMAs [13-15]. Nevertheless, replacing the fine mineral admixtures of cement mass, especially at high mass replacement, affects the characteristics of SCCs because of the variations in cement mass and in water/cement ratio.

The addition of fibers improves the flexural strength, toughness, and tensile strength of concrete. Numerous researchers have reported that adding fibers at volumetric ratios of $0.1 \%$ to $1.0 \%$ improves the strength and engineering properties of ordinary concrete [16-19]. The addition of fibers to concrete, however, has negligible effects on compressive strength and the modulus of elasticity. Moreover, the workability and flowability of SCRFCs decrease upon the addition of polypropylene fibers (PFs). The reduction of SCRFC workability due to the addition of fibers depends on many parameters, such as fiber type, dosage, and shape [20,21]. FA has been successfully added to SCC at replacement rates of up to $60 \%$ cement mass, and at a replacement rate of $35 \%$ cement mass to cement mixtures without the inclusion of PFs. Previous studies on the properties of SCCs have reported that replacing $30 \%$ of cement mass with FA produced concretes with excellent flowability and workability without the addition of fibers.

The goal of the present investigation is to study the properties of fresh and hardened SCC and SCRFC. In this study, FA was added at replacement rates of $0 \%, 20 \%, 40 \%$, and $60 \%$ cement mass. Then, PFs were added to the cement mixtures at a volumetric ratio of $0.22 \%$ to produce SCFRC. Segregation, bleeding, slump flow, slump flow T50, L-box V-funnel T5, and V-funnel tests were conducted on fresh concrete. In addition, the compressive, flexural, and tensile strengths of hardened concrete at ages $7,14,28$, and 90 days were investigated.

*Corresponding author: Abdullah Mohsen Ahmed Zeyad, Civil Engineering, College of Engineering, Jazan University, Jazan, Saudi Arabia, Tel: 506977655; E-mail: zeyad_eng@yahoo.com

Received May 21, 2017; Accepted May 24, 2017; Published May 28, 2017

Citation: Zeyad AMA, Saba AM (2017) Influence of Fly Ash on the Properties of Self-Compacting Fiber Reinforced Concrete. J Steel Struct Constr 3: 128. doi: 10.4172/2472-0437.1000128

Copyright: (C) 2017 Zeyad AMA, et al. This is an open-access article distributed under the terms of the Creative Commons Attribution License, which permits unrestricted use, distribution, and reproduction in any medium, provided the original author and source are credited. 


\section{Methods and Materials}

\section{Materials}

The tests carried out in order to study behavior the SCC during states the fresh and hardened concrete with (SCCF) and without polypropylene. The Slump flow, slump flow T50, L-box V-funnel T5, $\mathrm{V}$-funnel, segregation and bleeding tests are conducted during the fresh state. After casting then curing concrete samples in the water basin until the ages of testing, compressive, tensile and flexural strength tests have been carried out. Production of the SCC and SCCF requires application stringent on materials selecting and its quality, also determine the proportions all of the ingredients according to the mix design method, taking into consideration.

Cement: Ordinary Portland Cement (OPC) was used in the present investigation. Cement characterization tests were conducted in accordance with ASTM C150 [22]. Tables 1 and 2 have shown the chemical composition and physical characteristics of cement, respectively.

Fly ash: Fly ash meets the general requirements of ASTM C618 Class F [22]. Table 3 presents the chemical composition and physical characteristics of fly ash.

Aggregate: A crushed basalt rock with a maximum nominal size of $12.5 \mathrm{~mm}$ was used as a coarse aggregate (CA), and natural sand was used in the concrete mixtures as a fine aggregate (FA). The coarse and fine aggregate had a specific gravity (GS) of 2.63 and 2.71, and water absorptions (Wa) of 0.6 and $0.9 \%$ respectively.

Fine aggregate: The particle shapes and grade of FAs are important factors in SCC production. In this investigation, natural sand, which conforms to ASTM C33 specification, (ASTM, 2004) was used. Table 4 shows the grading analysis of FA.

Coarse aggregate: Table 4 shows that the grade of the coarse

\begin{tabular}{|c|c|c|c|}
\hline Oxide composition & Abbreviation & $\begin{array}{c}\text { Content } \\
\text { (percent) }\end{array}$ & $\begin{array}{c}\text { Limit of ASTM } \\
\text { specification }\end{array}$ \\
\hline Lime & $\mathrm{CaO}$ & 63.68 & $60-67$ \\
\hline Silica & $\mathrm{SiO} 2$ & 20.68 & $14-25$ \\
\hline Alumina & $\mathrm{AL2O} 3$ & 6.12 & $03-\mathrm{Aug}$ \\
\hline Iron Oxide & $\mathrm{Fe} 2 \mathrm{O} 3$ & 3.8 & $0.5-6$ \\
\hline Sulphate & $\mathrm{SO} 3$ & 2.68 & $01-\mathrm{Mar}$ \\
\hline Soda & $\mathrm{Na2O}$ & 0.29 & $0.2-1.3$ \\
\hline Potassa & $\mathrm{K} 2 \mathrm{O}$ & 0.42 & $0.2-1.3$ \\
\hline Magnesia & $\mathrm{MgO}$ & 1.21 & 0.144 \\
\hline Loss on Ignition & L. O. I & 1.55 & $£ 4$ \\
\hline Insoluble residue & $\mathrm{I} . \mathrm{R}$ & 0.63 & $£ 1.5$ \\
\hline Lime saturation factor & L. S. F & 0.91 & $0.66-1.02$ \\
\hline Tricalcium Silicate & $\mathrm{C} 3 \mathrm{~S}$ & 41.51 & $45-55$ \\
\hline Di Calcium Silicate & $\mathrm{C} 2 \mathrm{~S}$ & 28.16 & $20-30$ \\
\hline Tri Calcium Aluminate & $\mathrm{C} 3 \mathrm{~A}$ & 9.87 & $08-\mathrm{Dec}$ \\
\hline Tetra Calcium Alumina Ferrite & $\mathrm{C} 4 \mathrm{AF}$ & 11.57 & 43014 \\
\hline
\end{tabular}

Table 1: Percentage of Oxide Composition and Main Compounds.

\begin{tabular}{|l|c|c|}
\hline \multicolumn{1}{|c|}{ Physical properties } & $\begin{array}{c}\text { Test } \\
\text { Results }\end{array}$ & $\begin{array}{c}\text { Limit of } \\
\text { ASTM } \\
\text { specification }\end{array}$ \\
\hline Specific Surface area (Blaine method, $\mathrm{cm}^{2} / \mathrm{g}$ ) & 3220 & 2300.0 \\
\hline Initial Setting time, min & 120 & Min 30 \\
\hline Final Setting time, min & 480 & Mix 365 \\
\hline Compressive strength of mortar 14 days, $\mathrm{N} / \mathrm{mm}^{2}$ & 27 & Min 19 \\
\hline
\end{tabular}

Table 2: Cement Physical Properties.

\begin{tabular}{|c|c|c|}
\hline Oxides & Content \% & ASTM C 618 Class F \\
\hline $\mathrm{SiO}_{2}$ & 51.45 & \multirow[t]{3}{*}{$>70 \%$} \\
\hline $\mathrm{Fe}_{2} \mathrm{O}_{3}$ & 5.19 & \\
\hline $\mathrm{Al} 2 \mathrm{O}_{3}$ & 27.26 & \\
\hline $\mathrm{CaO}$ & 7.73 & - \\
\hline $\mathrm{MgO}$ & 5.16 & - \\
\hline $\mathrm{SO}_{3}$ & 0.5 & $5.0 \max$ \\
\hline $\mathrm{K} 2 \mathrm{O}$ & 2.5 & - \\
\hline L.O.I & 0.19 & $6.0 \max$ \\
\hline \multicolumn{3}{|c|}{ Physical Properties } \\
\hline Fineness (Blain) & $4020 \mathrm{~cm}^{2} / \mathrm{g}$ & - \\
\hline specific gravity & 2.32 & - \\
\hline
\end{tabular}

Table 3: Chemical Composition and Physical Properties of fly ash.

\begin{tabular}{|c|c|c|}
\hline \multirow{2}{*}{ Sieve size (mm) } & \multicolumn{2}{|c|}{$\%$ Passing by weight } \\
\cline { 2 - 3 } & Fine Aggregate & Coarse Aggregate \\
\hline 19 & 100 & 100 \\
\hline 12.5 & 100 & 95 \\
\hline 9.5 & 100 & 66.3 \\
\hline 4.75 & 96.4 & 4.3 \\
\hline 2.36 & 92.5 & 1.4 \\
\hline 1.18 & 78.4 & 0 \\
\hline 0.6 & 40.8 & 0 \\
\hline 0.3 & 11.6 & 0 \\
\hline 0.15 & 3.1 & 0 \\
\hline Fineness Modulus & 2.8 & - \\
\hline
\end{tabular}

Table 4: Grading of Coarse and Fine Aggregate.

\begin{tabular}{|c|c|}
\hline Properties & fiber \\
\hline Form & White color fibers \\
\hline Density & $0.91 \mathrm{~kg} / \mathrm{l}$ \\
\hline Fiber Length & $12 \mathrm{~mm}$ \\
\hline Fiber Diameter & $18 \mathrm{micron}$ \\
\hline Softening point & $160^{\circ} \mathrm{C}$ \\
\hline Specific surface area & $200 \mathrm{~m}^{2} / \mathrm{kg}$ \\
\hline Tensile strength (MPa) & $350 \mathrm{MPa}$ \\
\hline
\end{tabular}

Table 5: Physical properties of polypropylene fibers.

aggregate, which conforms to the ASTM C33 specifications (ASTM, 2004).

Polypropylene fibers: In this investigation, $12 \mathrm{~mm}$ PFs were used, some of their physical characteristics are provided in Table 5 .

Superplasticizer: High-reduce water range (HRWR) superplasticizer, a new generation of copolymer-based superplasticizer, designed for the production of self-compacting concrete (Viscocret 5030), was used in this study.

\section{Mix design methods}

Mix design methods for SCC differ considerably from the regular conventional concrete design. There are many mix design methods. Estimating the required batch weights involves sequence of steps. These steps fit a proportioning procedure that covers a combination of: selection of aggregate to provide the desired passing ability; a cementitious (powder)/water ratio and mortar-paste fraction ratio that have been historically proven to produce SCC with the required slump flow; and stability. These steps, in combination with the addition of the appropriate admixture technology, should yield a trial batch with the desired fresh SCC properties. The following is a summary of steps for determining performance requirements and proportioning of SCC mixes. 
- Step 1: Determine slump flow performance requirements;

- Step 2: Select coarse aggregate and proportion;

- Step 3: Estimate the required cementitious content and water;

- Step 4: Calculate paste and mortar volume;

- Step 5: Select admixture;

- Step 6: Make trial batch mixtures;

- Step 7: Test. When assessing the workability attributes of SCC (stability, filling ability, and passing ability), the slump flow test as well as a test to evaluate stability and passing ability (such as column segregation, or L-box) should be run; and

- Step 8: Adjust mixture proportions based on the test results and then re-batch with further testing until the required properties are achieved.

- The proportions of the concrete mixtures are summarized in Table 6.

\section{Mixture proportions}

The preliminary investigations of this study include evaluation of the equipment and test procedures, evaluation of the mixture proportioning method chosen, mixing procedure and replacement of the FA, PF and dosage of superplasticizer. Testing for these initial investigations is limited on fresh concrete properties.

Mixing and casting of specimens: In this investigation, the required quantities of materials were weighed for the correct mixing proportions. Then, cement was mixed with fly ash. The mixture was added to the coarse and fine aggregates. Then, all of the materials were mixed while dry for two minutes. Water was added to the mixtures in two stages: Half of the amount of water was initially added at the start of concrete mixing. The remaining water was then added after 30 $\mathrm{s}$ of concrete mixing. To obtain a homogeneous mixture, the concrete was continuously mixed for three min after the addition of water. After carrying out tests for fresh properties, mixing was immediately followed by casting. The top surface of the specimens was scraped to remove excess material and to achieve a smooth finish. The specimens were removed from molds after $24 \mathrm{~h}$ of storage under laboratory conditions. Storage conditions were in accordance with ASTM C192.

\section{Testing of the sample}

Fresh concrete tests: For determining SCC properties at fresh concrete state, the slump flow, slump flow T50, V-funnel, V-funnel T5, L-box, segregation and bleeding tests were applied. In order to reduce the influence of workability loss on tests' results of concrete samples, properties of fresh concrete were determined within 20 minutes of adding water.

The Flow test was performed in according with the European Guidelines for Self-Compacting Concrete (EFNARC) standards [23]. Flow test using the cone, which allows the flow and movement of the SCC of unimpeded to can be characterized.

It includes measuring slump flow diameter (D) after lifting the concrete cone, and in the same time measuring the time taken the concrete to spread in diameter $50 \mathrm{~cm}$ (T50).

V-funnel test was performed in according with EFNARC standards. $\mathrm{V}$-funnel is used to evaluate the fluidity, pass ability and segregation of self-compacting concrete. The test time of V-Funnel is the time in seconds from the opened the outlet at the in the bottom the device until seen the light from above. In order get good properties in a fresh concrete of SCC, it requires to have test time between 6 and 12 second.

L-box test was performed in according with EFNARC standards. L-box is used to assess the possibility of obstruction the filling capacity of the concrete in a confined construction elements. The filling capacity, determined as the ratio of the height the concrete in $\mathrm{H} 2$ at end of L-box with $\mathrm{H} 1$ at exit outlet $(\mathrm{H} 1 / \mathrm{H} 2)$, the ratio must be higher than 0.8 . Figure 1a-1d show fresh concrete tests.

Segregation test was conducted on ASTM C 1610. The segregation test is conducted by filling concrete into a $66 \mathrm{~cm}$ tall, $20 \mathrm{~cm}$ diameter column, which is split into 3 sections. The top and bottom sections are $16.5 \mathrm{~cm}$ inches in height and the middle section is $33 \mathrm{~cm}$ in height. The test apparatus is split into four sections based on an earlier version of the test. In this case, the middle two sections can be used as a single section. The concrete is left undisturbed for $15 \pm 1$ minutes, after which the concrete in the top and bottom sections is collected and washed over a No. 4 sieve to retain all coarse aggregate. The relative amounts of coarse aggregate in the top and bottom of the column is used as an indication of segregation resistance.

Bleeding test was conducted on ASTM C 232. During the test; maintain the ambient temperature between 18 and $24^{\circ} \mathrm{C}$. Immediately after troweling the surface of the specimen, record the time and determine the mass of the container and its contents. Place the specimen and container on a level platform or floor free of noticeable vibration and cover the container to prevent evaporation of the bleed water. Keep the cover in place throughout the test, except when drawing off the water. Draw off (with pipet or similar instrument) the water that has accumulated on the surface, at 10 min intervals during the first $40 \mathrm{~min}$ and at $30 \mathrm{~min}$ intervals thereafter until cessation of bleeding. To facilitate the collection of bleeding water, tilt the specimen carefully by placing a block approximately $50 \mathrm{~mm}$ thick under one side of the container 2 min prior to each time the water is withdrawn. After

\begin{tabular}{|c|c|c|c|c|c|c|c|}
\hline Mixture & Cement & Fly Ash & Coarse Aggregate & Fine Aggregate & $\begin{array}{l}\text { Poly-propylene } \\
\text { Fibers }\end{array}$ & Water & Super-plasticizer \\
\hline & \multicolumn{7}{|c|}{$\left(\mathrm{kg} / \mathrm{m}^{3}\right)$} \\
\hline $\operatorname{scc} 0$ & 500 & 0 & 794 & 809 & 0 & 200 & 7.5 \\
\hline SCCF & 500 & 0 & 794 & 809 & 0 & 200 & 7.5 \\
\hline $\operatorname{scc} 20$ & 400 & 100 & 794 & 809 & 0 & 200 & 7.5 \\
\hline SCCF20 & 400 & 100 & 794 & 809 & 2 & 200 & 7.5 \\
\hline $\operatorname{scc} 40$ & 300 & 200 & 794 & 809 & 0 & 200 & 7.5 \\
\hline SCCF40 & 300 & 200 & 794 & 809 & 2 & 200 & 7.5 \\
\hline $\operatorname{scc} 60$ & 200 & 300 & 794 & 809 & 0 & 200 & 7.5 \\
\hline SCCF60 & 200 & 300 & 794 & 809 & 2 & 200 & 7.5 \\
\hline
\end{tabular}

Table 6: Proportions of the concrete mixtures. 
Citation: Zeyad AMA, Saba AM (2017) Influence of Fly Ash on the Properties of Self-Compacting Fiber Reinforced Concrete. J Steel Struct Constr 3: 128. doi: 10.4172/2472-0437.1000128

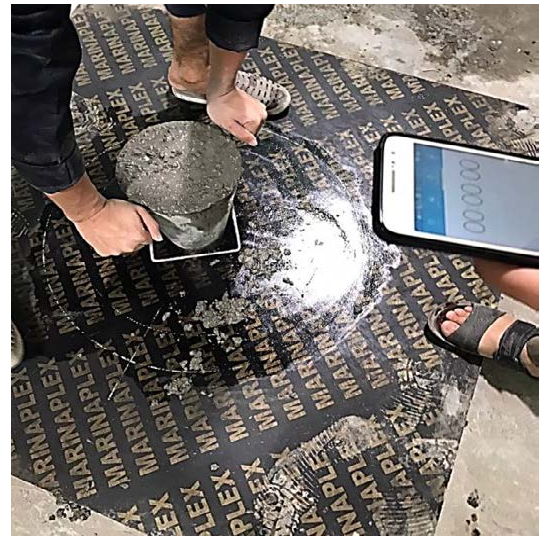

Figure 1a: Slump flow T50 test.

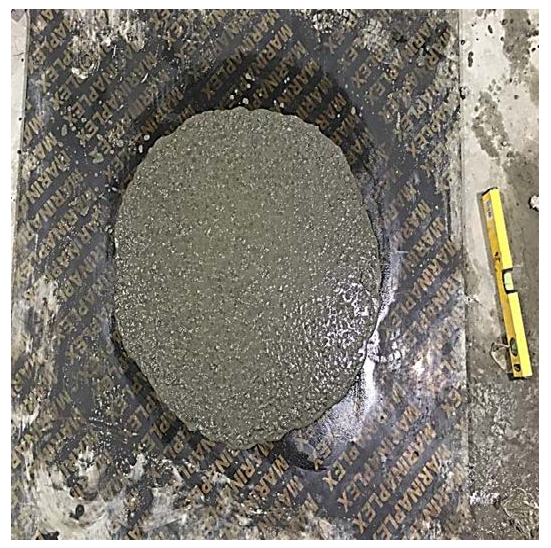

Figure 1b: Slump flow test.

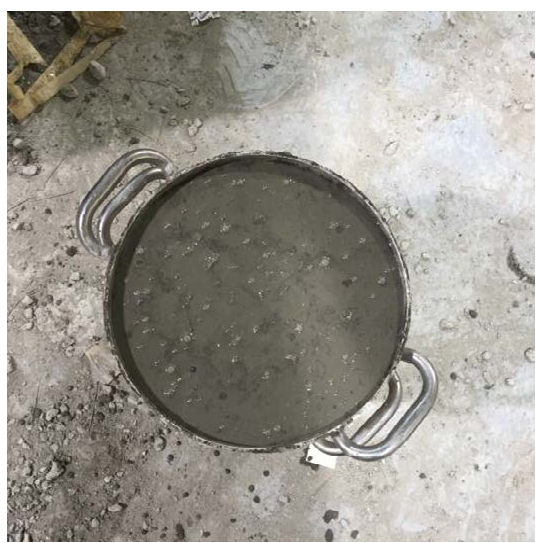

Figure 1c: Bleeding test.

the water is removed, return the container to a level position without jarring. After each withdrawal, transfer the water to a $100 \mathrm{~mL}$ graduate. Record the accumulated quantity of water after each transfer. When only the total volume of bleeding is desired to be determined, the periodic removal procedure shall be omitted and the entire amount removed in a single operation. If it is desired to determine the mass of the bleeding water and to exclude the material present other than the water, carefully decant the contents of the cylinder into a metal beaker.

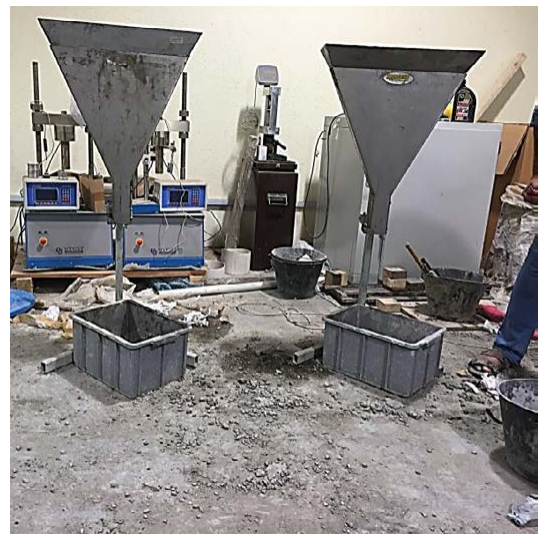

Figure 1d: V-Funnal test.

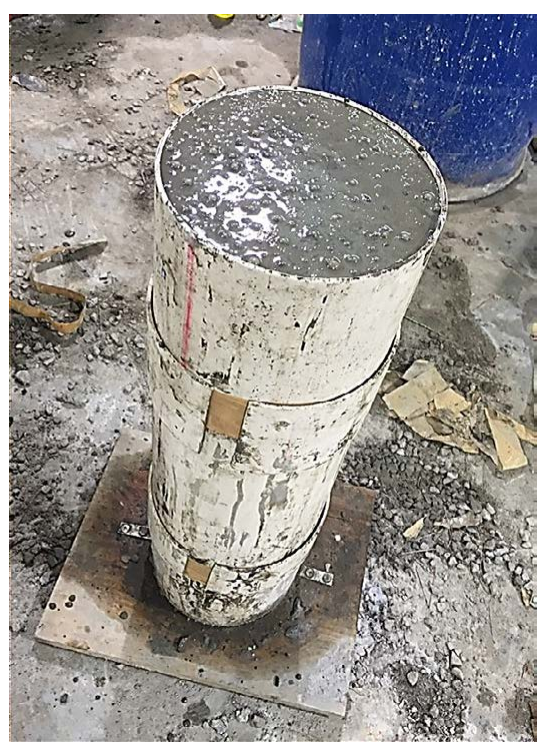

Figure 1e: Segregatin test.

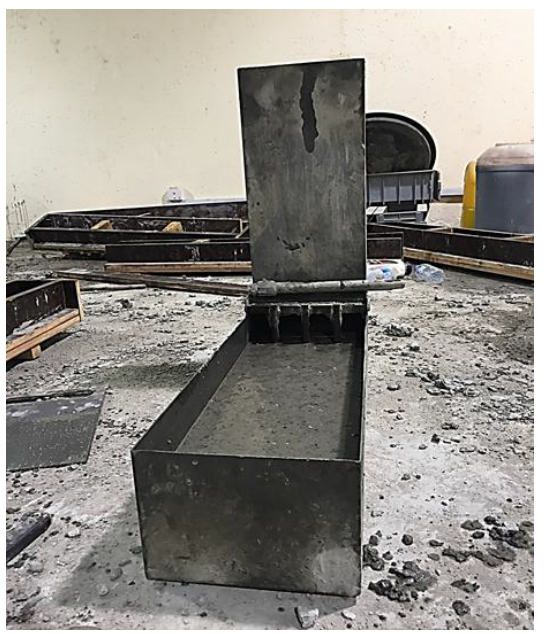

Figure 1f: L-Box test. 
Hardened concrete tests: In the state of hardened concrete, the tests that were carried out are compressive, indirect tensile and flexural strength. Compressive strength test according to ASTM C39 standard cubes measuring $150 \times 150 \times 150 \mathrm{~mm}$ were used. Indirect tensile tests were carried out according to ASTM C496. The dimensions of the standard cylinder are $150 \mathrm{D} \times 300 \mathrm{H} \mathrm{mm}$. Flexural tests were carried out according to ASTM C78. The dimensions of the standard prisms are $100 \times 100 \times 400 \mathrm{~mm}$. All tests were conducted at 7, 14, 28 and 90 days. The average value of the three specimens for each test age is determined and recorded.

\section{Results and Discussion}

\section{Properties of fresh concretes}

The results of the slump flow test are presented in Table 7. The results represent the maximum spread (the final diameter of slump flow) and T50, the time required for the concrete flow to fill a $50 \mathrm{~cm}$ diameter circle. EFNARC recommends that concrete mixtures should have slump flow diameters of $55 \mathrm{~cm}$ to $75 \mathrm{~cm}$ to be considered as selfcompacting mixture [24]. Slump flow that exceeds a $75 \mathrm{~cm}$ diameter may cause concrete to segregate, whereas that with less than a $55 \mathrm{~cm}$ diameter may indicate concrete with flow rates that are insufficient for passing through an overcrowded reinforcement. The results showed that concrete mixtures with PF (SCFRC) and without PF (SCC) and with the addition of FA at replacement rates of $20 \%$ and $40 \%$ cement mass met the slump flow requirements for SCCs. Concrete mixtures with the addition of FA at replacement rates of $0 \%$ and $60 \%$ cement mass exhibited low slump flow. Moreover, the results showed a wide range of variations, illustrating the effects of FA replacement rates and PF addition on SCC and SCRFC flowability. The decrease in the workability and flowability of SCC may be attributed to the addition of a high volume of FA as an alternative material. Slump flow rates increased by $40 \%$ and $34 \%$ when FA was added at replacement rates of $20 \%$ and $40 \%$ cement mass, respectively. The workability and flowability of all SCRFC mixtures were lower than those of all SCC mixtures. Moreover, the flowability SCC and SCFRC mixtures that contained FA at replacement rates of $0 \%$ and $60 \%$ cement mass did not meet the minimum requirements of the T50 test. Results also showed that the slump flow rates of SCFRCs decreased by $21 \%, 12 \%$, and $17 \%$ when FA was added at replacement rates of $0 \%, 20 \%$, and $40 \%$ cement mass, respectively. In general, increasing the replacement rates of FA from $20 \%$ to $40 \%$ cement mass did not significantly decrease the workability of concrete.Adding FA to cement at a replacement rate of $06 \%$ has a negative effect on properties of SCC.

In addition to the slump flow test and slump flow T50, the $\mathrm{V}$-funnel test was conducted to estimate the flowability of SCC and SCFRC mixtures. The V-funnel flow time was calculated in seconds between the time of the beginning of opening the bottom outlet until the light became noticeable from the bottom outlet. EFNARC recommends that concretes should have V-funnel flow times of $6 \mathrm{~s}$ to $12 \mathrm{~s}$ and a L-box

\begin{tabular}{|c|c|c|}
\hline Mixture & Slump flow $\mathbf{( c m )}$ & T50 (sec) \\
\hline SCC0 & 52 & 8 \\
\hline SCCF & 41 & - \\
\hline SCC20 & 73 & 2.3 \\
\hline SCCF20 & 64 & 5 \\
\hline SCC40 & 70 & 2.5 \\
\hline SCCF40 & 58 & 4 \\
\hline SCC60 & 47 & - \\
\hline SCCF60 & 46 & - \\
\hline & Table 7: Results of Slump flow Tests. \\
\hline
\end{tabular}

ratio $\mathrm{H} 2 / \mathrm{H} 1$ greater than 0.80 to be considered as SCCs (EFNARC, 2002).

Table 8 shows the results of V-funnel test and L-box. The results indicated that SCC and SCFRC mixtures that contained FA at replacement rates of $20 \%$ and $40 \%$ cement mass met the requirements for SCC. By contrast, SCC and SCFRC mixtures that contained FA at replacement rates of $0 \%$ and $60 \%$ cement mass did not meet the requirements for SCC. The decrease in the passing and filling abilities SCCs likely resulted from the high volume of added FA. Moreover, all SCRFC mixtures had lower passing and filling abilities than SCC mixtures. SCC and SCFRC mixtures containing FA at a replacement rate of $60 \%$ cement mass did not pass the $\mathrm{V}$-funnel and L-box $\mathrm{V}$-funnel T5 tests. The results suggested that increasing the replacement rate of FA to $60 \%$ cement mass exerted the greatest negative effect on the passing and filling abilities of the cement mixtures.

Table 9 shows the results of the bleeding and segregation tests. SCC and SCFRC mixtures that contained FA at replacement rates of $20 \%$ or $40 \%$ cement mass had high rates of bleeding and segregation. By contrast, SCC and SCFRC mixtures that contained FA at replacement rates of $0 \%$ or $60 \%$ cement mass had the lowest rates of bleeding and segregation. The addition of a high volume of FA likely decreased the bleeding and segregation of SCCs. Furthermore, the bleeding and segregation rates of SCFRC mixtures were lower than those of SCC mixtures.

\section{Compressive strength}

Figures 2-4 show the compressive strength test results for SCC and SCRFC at ages 7, 14, 28, and 90 days. Results showed that the evolution of compressive strength varied in SCC and SCRFC. The decline in compressive strength became apparent when FA replacement ratio increased to $60 \%$ cement mass. The decline in the compressive strength of SCC and SCRFC may be attributed to the addition of FA at the high replacement rate of $60 \%$ cement mass, which introduced air bubbles in hardened concrete and decreased compressive strength. The best compressive strength of SCCs at ages 7, 14, 28, and 90 days was obtained when FA was added at the replacement rate of $20 \%$. The compressive strength of SCCs increased by $16.1 \%, 7.4 \%, 3.9 \%$,

\begin{tabular}{|c|c|c|c|}
\hline Mixture & V-funnel (sec) & $\begin{array}{c}\text { V-funnel } \\
\text { (T5min.) (sec) }\end{array}$ & $\begin{array}{c}\text { L- Box ratio (H2) } \\
\text { H1) }\end{array}$ \\
\hline SCC0 & $\mathbf{1 0}$ & $\mathbf{1 7}$ & 0.76 \\
\hline SCCF & - & - & 0.55 \\
\hline SCC20 & $\mathbf{5 . 2}$ & $\mathbf{7}$ & 0.86 \\
\hline SCCF20 & $\mathbf{6 . 3}$ & $\mathbf{9}$ & 0.81 \\
\hline SCC40 & $\mathbf{5 . 3}$ & $\mathbf{8}$ & 0.88 \\
\hline SCCF40 & $\mathbf{7 . 6}$ & $\mathbf{1 0}$ & 0.89 \\
\hline SCC60 & $\mathbf{1 4}$ & $\mathbf{1 6}$ & 0.71 \\
\hline SCCF60 & $\mathbf{1 7}$ & $\mathbf{2 6}$ & 0.59 \\
\hline
\end{tabular}

Table 8: Results of L-box and v-funnel tests

\begin{tabular}{|c|c|c|}
\hline Segregation index, $\%$ & $\begin{array}{c}\text { Total bleeding water, } \\
\mathbf{m l}^{\mathbf{c} \mathbf{c m}^{2}}\end{array}$ & Mixture \\
\hline 3.2 & 0.08 & SCC0 \\
\hline 2.3 & 0 & SCCF \\
\hline 5.6 & 0.12 & SCC20 \\
\hline 3.5 & 0.09 & SCCF20 \\
\hline 7 & 0.18 & SCC40 \\
\hline 4.1 & 0.09 & SCCF40 \\
\hline 2.5 & 0.02 & SCC60 \\
\hline 1.8 & 0 & SCCF60 \\
\hline
\end{tabular}

Table 9: Results of bleeding and segregation tests. 
Citation: Zeyad AMA, Saba AM (2017) Influence of Fly Ash on the Properties of Self-Compacting Fiber Reinforced Concrete. J Steel Struct Constr 3: 128. doi: 10.4172/2472-0437.1000128

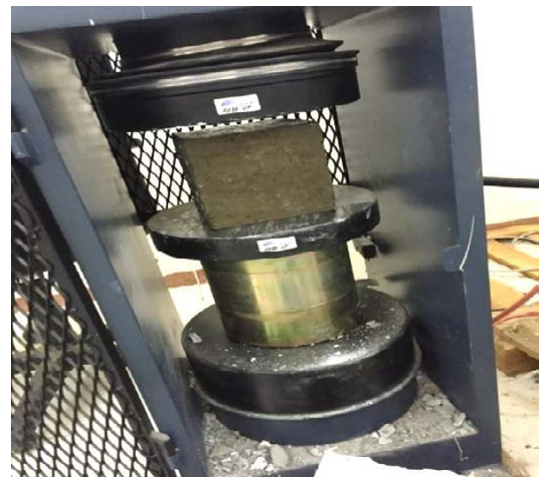

Figure 2a: compressive strength test.

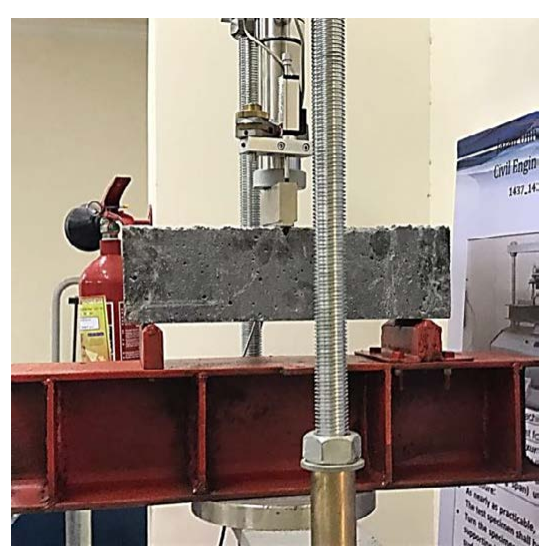

Figure 2b: fluxrral strength test.

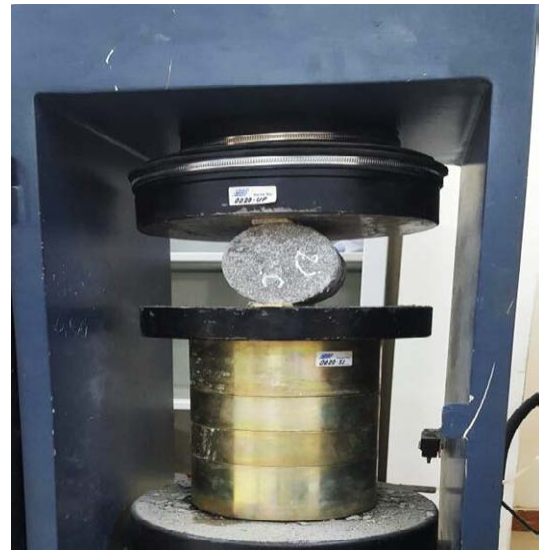

Figure 2c: Tensile strength test.

and $1.2 \%$ at ages $7,14,28$, and 90 days, respectively, when FA was added at the replacement rate of $20 \%$ cement mass. In addition, the compressive strength of SCCs increased by $8.5 \%$ and $1.5 \%$ at ages 7 and 82 days, respectively, when FA was added at the replacement rate of $40 \%$ cement mass. Compressive strength decreased by $18.8 \%$, $24.1 \%, 15.9 \%$, and $11.8 \%$ at ages $7,14,28$, and 90 days, respectively, when FA was added at the replacement rate of $60 \%$ cement mass. The compressive strength of SCRFCs s decreased compared with that of SCCs. Adding FA at the replacement rate of $60 \%$ cement mass greatly decreased the compressive strength of SCRFCs s. The percentages of

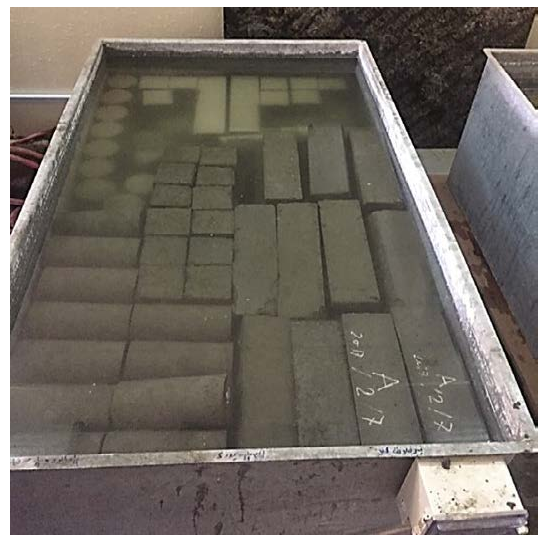

Figure 2d: Curing method.

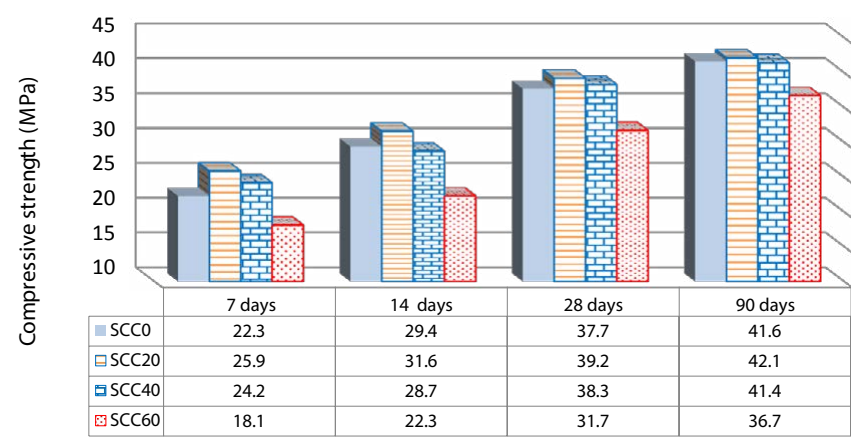

Figure 2e: Results of Compressive Strength Test of SCC.

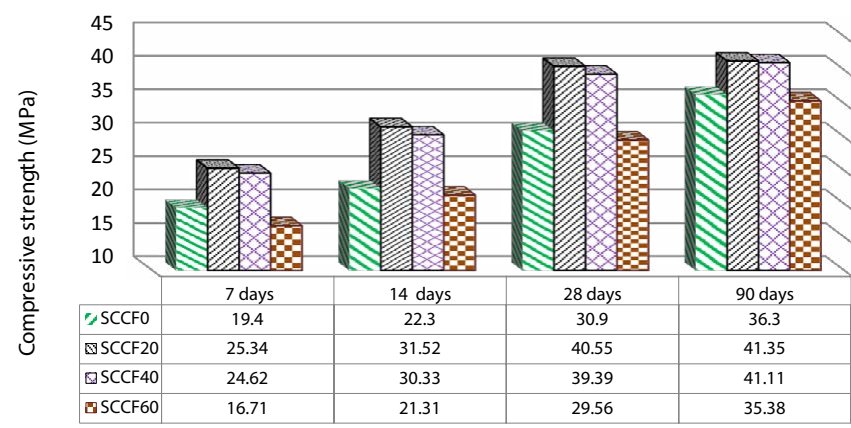

Figure 3: Results of Compressive Strength Test of SCCF.

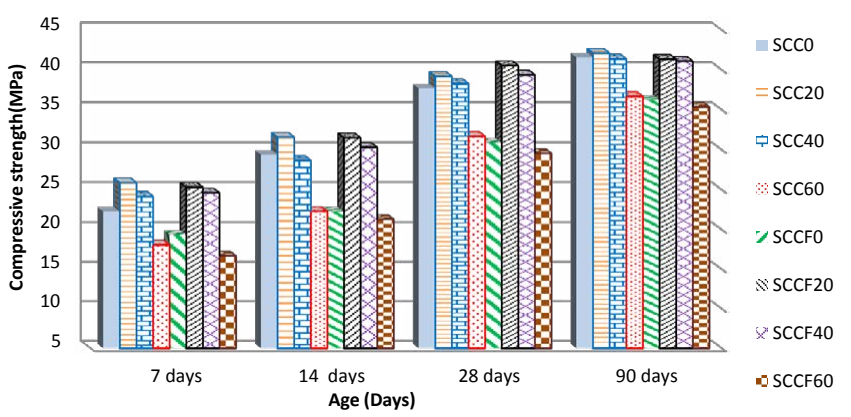

Figure 4: Results of Compressive Strength Test of SCC and CCF. 
Citation: Zeyad AMA, Saba AM (2017) Influence of Fly Ash on the Properties of Self-Compacting Fiber Reinforced Concrete. J Steel Struct Constr 3: 128. doi: 10.4172/2472-0437.1000128

decrease in compressive strength were higher in SCRFC mixtures. Thus, this finding may be attributed to the negative effect of fibers on concrete rheology, which affected the degree of concrete compaction and consequently decreased the compressive strength of concrete [25].

\section{Indirect tensile strength}

Figures 5-7 show the results of the indirect tensile strength for SCC and SCRFC mixtures at ages 7, 14, 28, and 90 days. The indirect tensile strength of SCRFC concrete slightly improved compared with that of SCC, thus suggesting that the addition of PFs improved the tensile strength of hardened concretes.

\section{Flexural strength}

Figures 8-10 show the results of flexural strength for SCC and SCRFC mixtures at ages 7, 14, 28, and 90 days, respectively. The results showed that indirect tensile strength of SCRFC slightly improved

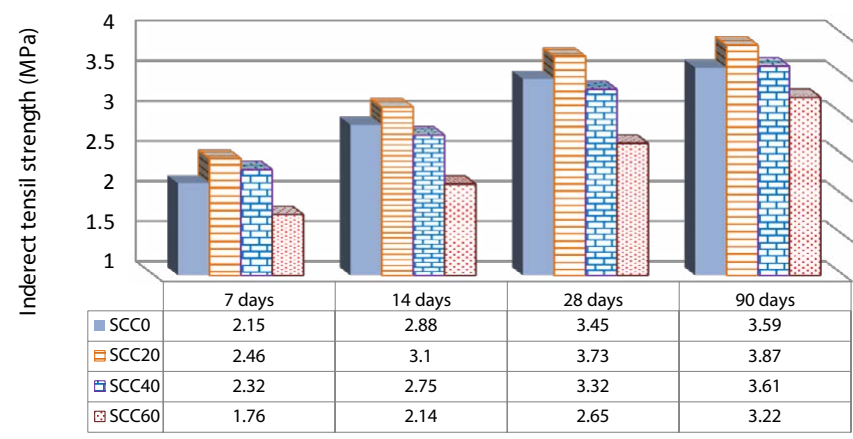

Figure 5: Results of Indirect Tensile Strength Test of SCC.

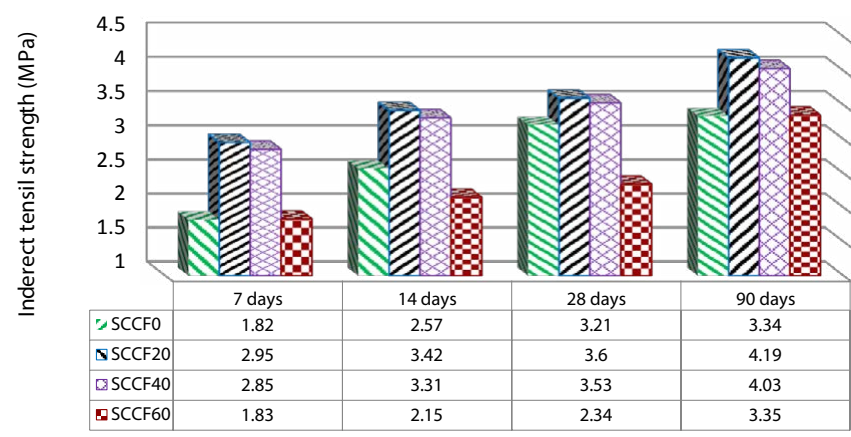

Figure 6: Results of Indirect Tensile Strength Test of SCCF.

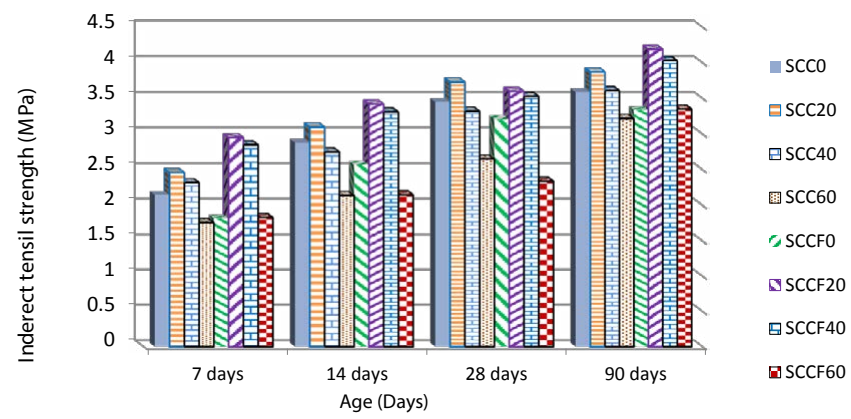

Figure 7: Results of Indirect Tensile Strength Test of SCC and SCCF.

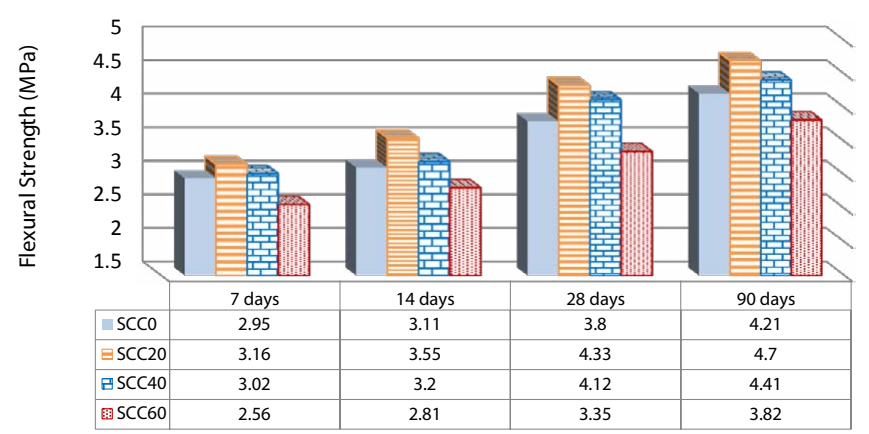

Figure 8: Results of Flexural Strength Test of SCC.

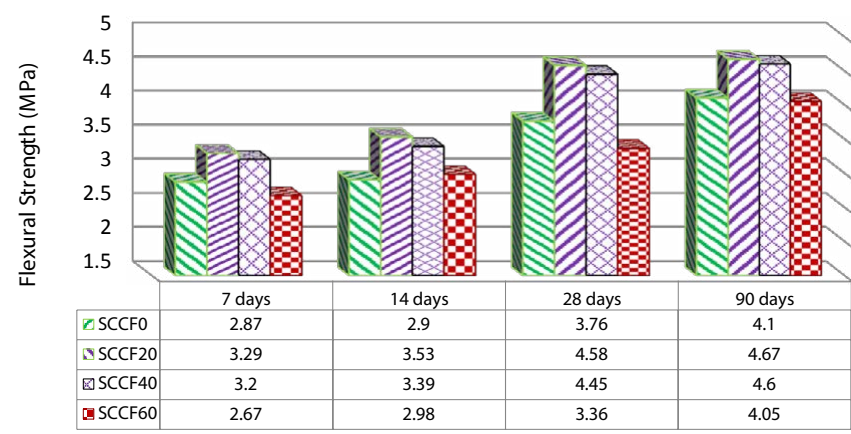

Figure 9: Results of Flexural Strength Test of SCCF.

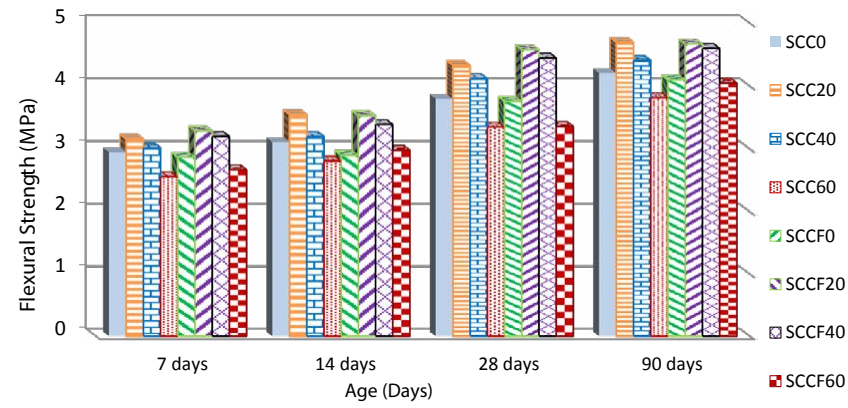

Figure 10: Results of Flexural Strength Test.

compared with that of SCC, indicating that the addition of PFs improves the flexural strength of hardened concretes.

\section{Conclusions}

The following conclusions were drawn from the results of this study:

1. The addition of FA positively affected the properties of fresh concrete and the compressive strength of mixtures at all ages.

2. SCCs with and without PFs were obtained by adding FA at the replacement rates up to $40 \%$ cement mass.

3. The best SCC workability was obtained when FA was added at replacement rates of $20 \%$ and $40 \%$ cement mass without PFs. Fresh SCC samples with this formulation exhibited slump flow diameters of $73 \mathrm{~cm}$ and $70 \mathrm{~cm}$; blocking ratios of 0.86 and 0.88 ; and flow times of 5.2 to $5.3 \mathrm{~s}$.

4. Based on the test results, FA should be utilized to produce SCC 
Citation: Zeyad AMA, Saba AM (2017) Influence of Fly Ash on the Properties of Self-Compacting Fiber Reinforced Concrete. J Steel Struct Constr 3: 128. doi: 10.4172/2472-0437.1000128

with high strength at 90 days. Compressive strength reached $41 \mathrm{MPa}$ when FA was added at replacement rates of $20 \%$ and $40 \%$ cement mass to SCC and SCRFC.

5. The addition of FA at different replacement ratios to SCC and SCRFC mixtures exerted different effects. Thus, for reasons of economy, FA should be added to SCCs and SCRFCs s at replacement rates of $20 \%$ to $40 \%$ cement mass.

- The addition of PFs decreased the properties of fresh concrete but improved flexural and indirect tensile strengths.

\section{References}

1. Brouwers H, Radix H (2005) Self-compacting concrete: theoretical and experimental study. Cement and Concrete Research 35: 2116-2136.

2. Nanthagopalan $P$, Santhanam M (2011) Fresh and hardened properties of selfcompacting concrete produced with manufactured sand. Cement and Concrete Composites 33: 353-358

3. Okamura H, Ouchi M (2003) Self-compacting concrete. Journal of Advanced Concrete Technology 1: 5-15.

4. Ramanathan P, Baskar I, Muthupriya P, Venkatasubramani R (2013) Performance of self-compacting concrete containing different mineral admixtures. KSCE Journal of Civil Engineering 17: 465-472.

5. Uysal M, Sumer M (2011) Performance of self-compacting concrete containing different mineral admixtures. Construction and Building Materials 25: 4112 4120 .

6. Siddique R (2011) Properties of self-compacting concrete containing class F fly ash. Materials \& Design 32: 1501-1507.

7. Gesoglu M, Ozbay E (2007) Effects of mineral admixtures on fresh and hardened properties of self-compacting concretes: binary, ternary and quaternary systems. Materials and Structures 40: 923-937.

8. Mohammadhosseini $H$, AWAL AA, Ehsan AH (2015) Influence of palm oil fue ash on fresh and mechanical properties of self-compacting concrete. Sadhana 40: $1989-1999$.

9. Safiuddin M, West J, Soudki K (2011) Flowing ability of the mortars formulated from self-compacting concretes incorporating rice husk ash. Construction and Building Materials 25: 973-978.

10. Ashtiani MS, Scott AN, Dhakal RP (2013) Mechanical and fresh properties of high-strength self-compacting concrete containing class $C$ fly ash. Construction and Building Materials 47: 1217-1224.

11. Celik K, Meral C, Mancio M, Mehta PK, Monteiro PJ (2014) A comparative study of self-consolidating concretes incorporating high-volume natural pozzolan or high-volume fly ash. Construction and Building Materials 67: 14-19.

12. Siddique R, Aggarwal $P$, Aggarwal $Y(2012)$ Influence of water/powder ratio on strength properties of self-compacting concrete containing coal fly ash and bottom ash. Construction and Building Materials 29: 73-81.

13. Cyr M, Mouret M (2003) Rheological characterization of superplasticized cement pastes containing mineral admixtures: consequences on selfcompacting concrete design. Special Publication 217: 241-256.

14. Felekoğlu B, Türkel S, Baradan B (2007) Effect of water/cement ratio on the fresh and hardened properties of self-compacting concrete. Building and Environment 42: 1795-1802.

15. Ouchi M, Hibino M, Okamura H (1997) Effect of superplasticizer on selfcompactability of fresh concrete. Transportation Research Record Journal of the Transportation Research Board 1574: 37-40.

16. Al-Qadi A, Mustapha K, Nagathan S, Al-Kadi Q (2011) Effect of polypropylene fibres on fresh and hardened properties of self-compacting concrete at elevated temperatures. Australian Journal of Basic and Applied Sciences 5: 378-384.

17. Banthia N, Gupta R (2006) Influence of polypropylene fiber geometry on plastic shrinkage cracking in concrete. Cement and Concrete Research 36: 12631267.

18. Islam GS, Gupta SD (2016) Evaluating plastic shrinkage and permeability of polypropylene fiber reinforced concrete. International Journal of Sustainable Built Environment 5: 345-354

19. Mohamed R (2006) Effect of polypropylene fibers on the mechanical properties of normal concrete. Journal of Engineering Sciences, Assiut University 34 1049-1059.

20. Corinaldesi V, Moriconi G (2011) Characterization of self-compacting concretes prepared with different fibers and mineral additions. Cement and Concrete Composites 33: 596-601.

21. El-Dieb A, Taha MR (2012) Flow characteristics and acceptance criteria of fiber-reinforced self-compacted concrete (FR-SCC). Construction and Building Materials 27: 585-596.

22. ASTM (2004) Annual book of ASTM standards. ASTM International.

23. Concrete SC (2005) The European Guidelines for Self-Compacting Concrete.

24. EFNARC (2002) Specification and guidelines for self-compacting concrete. In European Federation of National Associations Representing producers and applicators of specialist building products for Concrete (EFNARC), p: 32

25. Akinpelu MA, Odeyemi SO, Olafusi OS, Muhammed FZ (2017) Evaluation of splitting tensile and compressive strength relationship of self-compacting concrete. Journal of King Saud University-Engineering Sciences. 